\title{
Root dynamics and survival in a nutrient-poor and species-rich woodland under a drying climate
}

\author{
François P. Teste (D) Victoria A. Marchesini • \\ Erik J. Veneklaas • Kingsley W. Dixon • Hans Lambers
}

Received: 22 February 2017 / Accepted: 22 June 2017

(C) Springer International Publishing AG 2017

\begin{abstract}
Background and aims In Australia's Mediterranean hyperdiverse vegetation, species that produce cluster roots to mobilise poorly-available nutrients (e.g. Banksia spp.) are an important functional and structural component. Cluster roots are only active during the wet season, indicating a strong dependence on suitable surface soil moisture conditions. Winter rainfall in this region is declining due to global climate change, with a delayed commencement of rains and a decline in precipitation. It is unknown how lower soil moisture levels will affect the root dynamics of these globallysignificant plant communities.
\end{abstract}

Responsible Editor: Michael Luke McCormack

Electronic supplementary material The online version of this article (doi:10.1007/s11104-017-3323-9) contains supplementary material, which is available to authorized users.

F. P. Teste · V. A. Marchesini - E. J. Veneklaas •

K. W. Dixon $\cdot$ H. Lambers

School of Biological Sciences, The University of Western Australia, 35 Stirling Highway, Crawley (Perth), WA 6009, Australia

F. P. Teste $(\bowtie) \cdot$ V. A. Marchesini

Grupo de Estudios Ambientales, IMASL-CONICET \&

Universidad Nacional de San Luis, Av. Ejercito de los Andes 950

(5700), San Luis, Argentina

e-mail: francois.teste@uwa.edu.au

K. W. Dixon

Department of Environment and Agriculture, Curtin University, Kent Street, Bentley, WA 6102, Australia
Methods We determined the root dynamics and root lifespan with minirhizotrons with or without irrigation to simulate reduced rainfall scenarios.

Results We found a major effect of irrigation on the early production $\left(0.24 \mathrm{~m} \mathrm{~m}^{-2} \mathrm{~d}^{-1}\right.$ increase $)$, occurrence (97\% increase) of cluster roots and only slight effects on lifespan ( $~ 10$ days less) of all root types. With irrigation, the resultant greater soil moisture levels increased the deployment of cluster roots. Apart from cluster roots, the dynamics of other roots did not decline at lower soil moisture levels, suggesting that this system shows some resilience to decreased rainfall.

Conclusions Future research should focus on assessing if climate-altered cluster-root activity may be promoting compositional shifts in plant communities with additional restraining effects on root trait diversity.

Keywords Banksia attenuata . Cluster-root emergence · Mediterranean climate change $\cdot$ Minirhizotron $\cdot$ Root lifespan and longevity $\cdot$ Soil moisture

\section{Introduction}

The southwest of Australia has a Mediterranean climate and hosts a globally-recognised biodiversity hotspot (Myers et al. 2000) with many plant species relying on diverse nutrient-acquisition strategies to gather nutrients from soils that are extremely infertile and with poor water-holding capacity (Lambers et al. 2014). Some of the most prominent plant species in these hyperdiverse plant communities produce cluster roots (e.g., Banksia 
species), a very efficient strategy to gather phosphorus (P) from soils with very low P availability (Lambers et al. 2015). The production of cluster roots is greatly stimulated by elevated surface soil moisture levels (Lamont 2003). Therefore, the 'Achilles heel' of this strategy appears to be a minimum-threshold change in soil moisture level that signals the plant to produce cluster roots to enhance P uptake from soil (Lamont 1976, 2003). However, fundamental effects of declining soil moisture levels on the general dynamics and lifespan of these cluster roots remains poorly explored in field studies in situ.

Mediterranean ecosystems in general, and particularly in southwest Australia, are experiencing drying climates due to climate change (Indian Ocean Climate Initiative 2012; Diffenbaugh and Field 2013). These ecosystems may be among the most significantly affected by climate change due to their dependence on reliable winter-rainfall (Indian Ocean Climate Initiative 2012). Decreasing winter rains and delays in the onset of precipitation, is expected to not only affect the root dynamics and lifespan of most plants growing in these ecosystems, but particularly the plants that rely on cluster roots to acquire poorly-mobile nutrients such as P. Fine-root production is adequately explained by factors such as precipitation at a global scale (Finér et al. 2011); yet there are very few studies focused on root ecology in biodiverse Mediterranean ecosystems with no studies on root dynamics to reliably draw conclusions on the effect of decreasing soil moisture on root activity and subsequent plant ecological responses.

In the context of global climate change, there is a fundamental need for root ecology data from field studies in Mediterranean ecosystems experiencing drying trends. Such data will underpin our understanding of the ecological implications of lower soil moisture levels on cluster-root dynamics in particular, but also on root dynamics and ecosystem function in general (Finér et al. 2011). Once these fundamental root ecological studies have been conducted, we can begin to answer questions concerning cluster-root functioning and their role as key P-mining structures in P-impoverished soil under a drying climate, or will their lifespan be shortened and further reduce $\mathrm{P}$ availability in these Mediterranean ecosystems? Pulse-growth in roots has been observed in response to precipitation bursts in various ecosystems such as temperate forests, steppes and deserts (Huang and Nobel 1992; Johnson et al. 2006; Phillips et al. 2006; Bai et al. 2010), yet it is unknown if Mediterranean systems will respond similarly.

Primary productivity in biodiverse Mediterranean plant communities is generally P-limited (Laliberté et al. 2012). Therefore, if cluster-rooted plants, having a very efficient 'P-mining' strategy in this ecosystem (Lambers et al. 2006), are affected by lower soil moisture levels, then there may be species compositional shifts. Up to sixty years of vegetation surveys in remnant Banksia woodlands (e.g., Kings Park and Bold Park, Perth, WA, Australia) show that, indeed, compositional shifts in plant communities are occurring (Crosti et al. 2007; Fisher et al. 2009). Furthermore, recent studies indicate that these P-mining plants can facilitate the uptake of growth-limiting nutrients for coexisting plant species (Muler et al. 2014; Teste et al. 2014). Thus, if patterns of cluster-root formation are modified under a drying climate, then, ultimately, coexisting plant species that rely on some level of facilitated nutrient uptake may also be affected.

To gain a better understanding of root dynamics in a drying climate, we set up a field experiment with and without irrigation in a diverse eucalypt-banksia woodland in southwest Australia. We used Banksia attenuata as our focal tree that produces large compound cluster roots (Shane and Lambers 2005; Denton et al. 2007). We then monitored root dynamics of all roots near the B. attenuata trees with minirhizotron tubes and cameras before and after the start of the rainy winter months. The aims of the study were to determine: i) are root dynamics (standing crop, mortality, and production) increased by greater soil moisture conditions?; ii) what is the lifespan of the major identifiable root types (cluster roots, woody roots, and herbaceous roots) in a diverse eucalyptbanksia woodland, and does a decrease in soil moisture content reduce lifespan?; and iii) are cluster roots comparatively more frequent when soil moisture levels are greater? We also examined the lifespan of rootlets emerging from cluster-rooted plants in situ under field conditions to inform our future work on nutrient mobilisation-based facilitation (sensu Wright et al. (2017); Lambers et al. submitted; Teste et al. unpublished data). This is the first in situ study of cluster roots and other root types in a Banksia woodland, where the implications of varying soil moisture levels on their dynamics were investigated. Cluster-rooted plants are a prominent group with keystone functions, so reductions in arrival time and total amount of adequate soil 
moisture levels (due to climate change) may delay and reduce the formation and activity of cluster roots which may then alter the cycling of phosphorus and potentially shift plant community compositions.

\section{Materials and methods}

Study site

Research plots were established at The University of Western Australia's (UWA) Shenton Park Field Station $\left(31.96^{\circ} \mathrm{S}, 115.79^{\circ} \mathrm{E}\right)$ (Fig. 1). The field station hosts a high quality remnant eucalypt-(Eucalyptus gomphocephala) banksia woodland, dominated by Banksia attenuata, Banksia menziesii, Eucalyptus marginata, Allocasuarina fraseriana, and Xanthorrhoea preissii. The UWA field station is located in the kwongan vegetation type on the Swan Coastal Plain within the Southwest Australian Floristic Region (sensu Hopper and Gioia 2004), and is part of the Spearwood coastal dune system (McArthur and Bettenay 1974; Wyrwoll et al. 2014). Soils are characterised by deep well-drained, nutrient-poor sand deposited more than 120,000 years ago as dunes along the Indian Ocean. The climate is Mediterranean with a mean annual temperature of $19.2{ }^{\circ} \mathrm{C}$ (mean minimum $=13.8{ }^{\circ} \mathrm{C}$; mean maximum $=24.6{ }^{\circ} \mathrm{C}$ ) and rainfall of $702 \mathrm{~mm}$ (Australia's Bureau of Meteorology; http://www.bom.gov.au/climate/data/; 1967 to 2011).

Experimental design

In May 2011, 40 minirhizotron clear tubes (Bartz Technology Corp., Carpinteria, CA, USA, internal diameter $=5.08 \mathrm{~cm}$ ) were installed at $30^{\circ}$ and $60^{\circ}$ angles, to an effective depth of $50 \mathrm{~cm}$ at $1 \mathrm{~m}$ and $2.5 \mathrm{~m}$ from the basal stem of ten Banksia attenuata focal trees (i.e. on 10 plots). The top $10 \mathrm{~cm}$ of the tubes were painted over twice with black and white paint to eliminate light interference. The tubes were also insulated with a roll of $15 \mathrm{~cm}$ long foam under the top cap to minimise the influence of external air temperature. All tubes were capped at both ends. All tubes were randomly assigned a cardinal direction around the focal tree. Installed tubes were left to stabilise for 11 months prior to capturing the first images with a custom-built minirhizotron camera that gave us high resolution images of the minirhizotron tubes for these initial measurements. Due to technical difficulties we then switched to capturing images with the BTC2 Minirhizotron Video Microscope (Bartz Technology Corp., Carpinteria, CA, USA) for the remainder of the study. The field of view for the BTC2 camera is $1.35 \mathrm{~cm}$ vertical by $1.8 \mathrm{~cm}$ horizontal and it has a $15 \times$ magnification. In June 2011, plots were sprayed with a grass-selective herbicide (fluazifop-p
Fig. 1 Location of the research plots (white triangle) where this study on root dynamics using minirhizotron tubes took place. Also shown is a photo of the irrigation treatment in action on Plot 6 with a Banksia attenuata focal tree in the center with whitecapped minirhizotron tubes all around. Plots were situated in remnant eucalypt-(Eucalyptus gomphocephala) banksia woodland of the UWA Shenton Park Field Station $\left(31^{\circ} 56^{\prime} \mathrm{S}, 115^{\circ} 47^{\prime}\right.$ E) that is part of the Swan Coastal Plain ecoregion, Western Australia

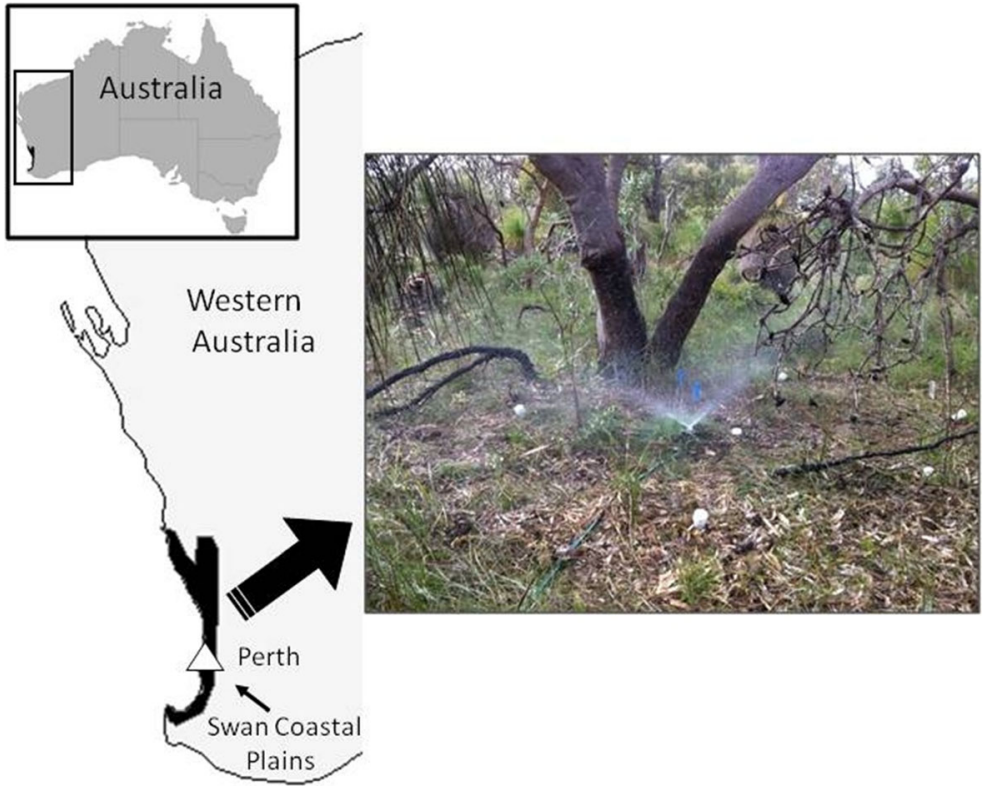


butyl, Fusilade ${ }^{\circledR}$, Syngenta AG, Basel, Switzerland) according to the manufacturer's instructions to control the invasive South African grass Ehrharta calycina (veld grass).

\section{Irrigation treatment}

In April 2012, circular sprinkler systems were installed at the base of each focal tree in five randomly selected plots (Fig. 1). Water was sprayed evenly to a distance of $4 \mathrm{~m}$ and thus wetted the areas monitored by minirhizotron tubes. We started the irrigation treatment a month before the winter rains started and produced a $25 \%$ increase in monthly winter water inputs (from April to October) based on 45 years of rainfall data (1967 to 2011) from a nearby weather station (Subiaco treatment plant, Station \# 009151, Lat: $31.96^{\circ} \mathrm{S}$, Long: $115.79^{\circ} \mathrm{E}$; Bureau of Meteorology, http://www.bom. gov.au/climate/averages/). We irrigated the plots every month and by October we had added a total of $148 \mathrm{~mm}$ of supplementary water to each plot.

Image capture and analysis

Roots in the minirhizotron tubes were first imaged on April 4, 2012 with the custom-built minirhizotron camera until the end of May 2012 and then with the BTC2 camera until the end of the study on 5 October, 2012 (Fig. S1). We simultaneously monitored soil moisture with a Diviner 2000 electro-magnetic soil moisture probe (Sentek Pty Ltd., Stepney, SA, Australia) at five depths $(0,10,20,30,40$, and $50 \mathrm{~cm})$ along an additional two white PVC tubes per plot that were installed vertically (i.e. at $90^{\circ}$ to the soil surface). Following the manufacturer's instructions, we calibrated the probe's output with soil samples from the experimental plots to generate volumetric soil moisture content $(\%)$ values. Thereafter, we monitored root dynamics and soil moisture on a weekly basis when possible. Root growth near the soil surface around minirhizotron tubes is typically hindered (Smit et al. 2000); thus we imaged from a starting depth of $\sim 2.9 \mathrm{~cm}$ from the soil surface.

We used Rootfly v. 2.0.2, an open-sourced software application, to analyse the minirhizotron images (Zeng et al. 2010). Rootfly allowed us to measure the number of roots, root length, the type of root (cluster, woody or herbaceous roots based on structure and colour; Fig. S9S10), and the birth and death rates of roots through time at various soil depths. Whether woody roots originated from woody plant species was not explicitly determined, since there are perennial herbaceous plant species that also produce woody roots in this system (Dodd et al. 1984). Each root was annotated and its length traced with a computer mouse. We did not trace the width of the roots (i.e. root diameter) as we found it too inaccurate using images captured with the BTC2 camera, particularly for the fine roots. Furthermore, since root diameter was not traced and we only distinguished the root types based on structure and colour, we did not attempt to distinguish differences among the woody root types beyond this general framework. For cluster roots, we drew one plane of the cluster, since in Banksia attenuata cluster roots form fan-like symmetrical structures referred to as 'compound type', which embodies a main axis and fine rootlets (Shane and Lambers 2005). In this study the minirhizotron approach was used to give an estimate of root production and survival over time in a non-destructive manner. For further details about cluster root structure we refer to previous studies (Shane and Lambers 2005; Lambers et al. 2014).

\section{Vegetation surveys}

Between 2012 and 2013, we identified all plant species and their abundances on each plot within a $4 \mathrm{~m}$ radius from the base of the focal tree (Table S2). Vegetation analyses after plot selection were used to determine how similar the irrigated and non-irrigated plots were to each other and if any major confounding factors appeared to exist. We did not find any significant differences in key plant community characteristics between irrigated and non-irrigated plots (Fig. S2) or any major shifts in the relative abundance of nutrient-acquisition strategies (Fig. S3).

\section{Data analysis}

Analysis of minirhizotron images provided measurements of number of roots, root length (per unit frame area $\mathrm{m} \mathrm{m}^{-2}$ ), root type (herbaceous, woody, cluster root, or rootlet) at repeatable locations through soil depth and time. For every image, we calculated standing crop as the measure of the length of all live roots. Root production over the 181 days of imaging was calculated as the length of newly appeared roots plus root extensions of existing roots. Root mortality was calculated as the length of non-recurring roots plus the length of roots 
that appeared dead based on visual cues such as diameter decrease and/or dark brown colouration.

To determine differences in standing crop, root production, and root mortality between sampling months, we performed a repeated measures analysis of variance (ANOVA) with linear mixed effects models. Mean values per month were used regardless of the number of weekly observations per month. We then used Tukey HSD tests to compare means to determine if there were any specific differences between two sampling months. We used a proportional-hazards regression model also known as Cox regression or Cox proportional hazard model (Therneau and Grambsch 2000) to analyse the survival of roots with the irrigation treatment and according to root type and rooting depth. When the global test for the model was significant, we further tested if there was a difference between two or more survival curves using the $G$-rho family of tests, with the log-rank and with the Peto \& Peto modification of the Gehan-Wilcoxon test (Harrington and Fleming 1982). We did not find any significant differences between the two installation angles of the minirhizotron tubes thus data were pooled. All graphing and statistical analyses were conducted in R ( R Core Team 2016) with the 'survival' and 'ggplot2' packages (Wickham 2009; Therneau 2014).

\section{Results}

\section{Rainfall and soil moisture}

The recent (1975 to 2012) rainfall trend shows a tendency for less overall rainfall and later arrival of winter rainfall (Fig. S4). The rainfall in 2012 was below historical averages and was marked by two large rain events, one in late April and the other in early September, and a dry spell during mid-May and early June, followed by below-average rainfall during the traditionally wet winter months (May to August, Fig. 2). The irrigation treatment produced a total of $148 \mathrm{~mm}$ of supplementary water, which represents a $25 \%$ greater amount of water (i.e. rainfall) over monthly recorded averages (between 1967 and 2011) but was actually $23.1 \%$ greater than the recorded 2012 rainfall, the year of this study. As a result, the irrigation treatment produced an overall mean of $91 \mathrm{~mm}$ of water input per month during the imaging months (April to October) comparable to the $97 \mathrm{~mm}$ based on long-term average (pre-1975 as in Fig. 2), whereas the nonirrigated plots received an overall mean of $73 \mathrm{~mm}$ of rainfall per month. As expected, the irrigation treatment considerably increased soil moisture content of the experimental plots (Fig. 2, Fig. S5). Soil moisture levels in the upper $10 \mathrm{~cm}(14.6 \%)$ were lower than those between 11 and $50 \mathrm{~cm}(15.0 \%)$ (Fig. S5).

a)

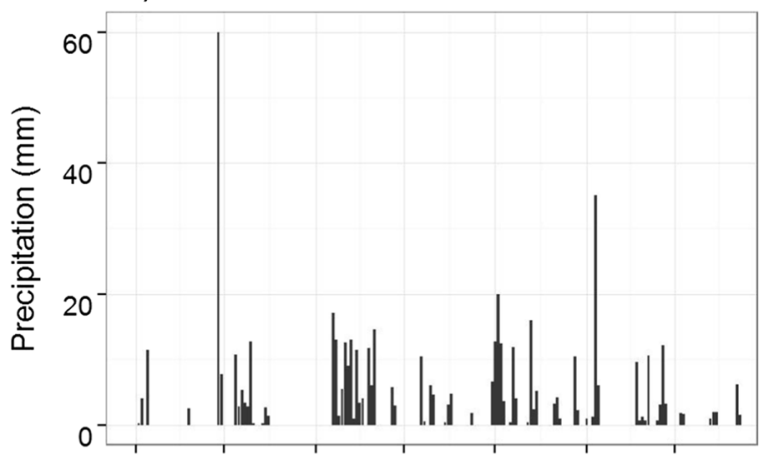

b)

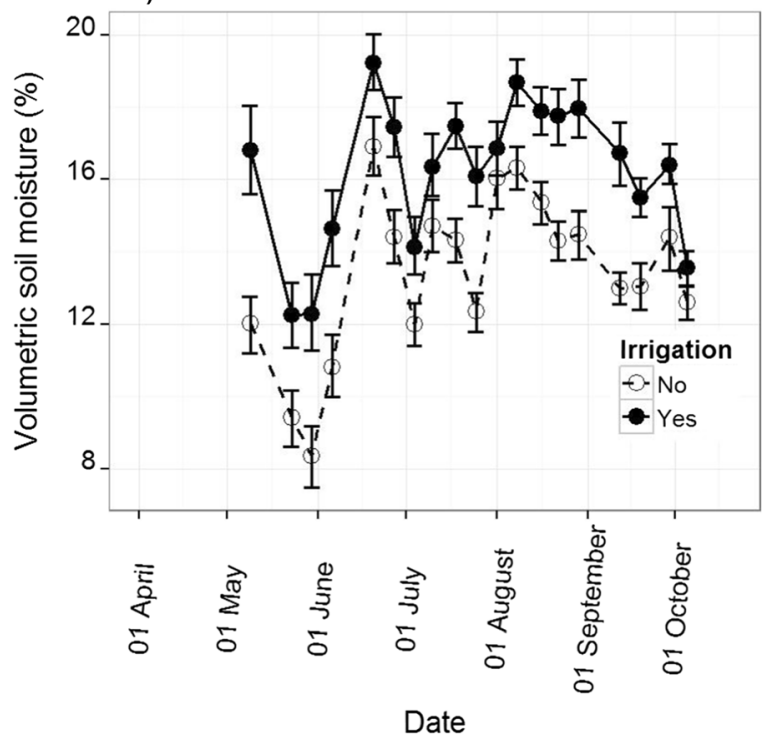

Fig. 2 a) Precipitation (i.e. rainfall) and b) soil moisture (depth $=0$ to $50 \mathrm{~cm}$ ) during the 2012 measurement period in a eucalyptbanksia woodland at the Shenton Park Field Station. Daily rainfall values were obtained from the nearest weather station. Soil moisture content as measured with a Diviner 2000 probe and calibrated with volumetric soil moisture content $(\%)$. Soil moisture values are means with $95 \%$ confidence intervals. Irrigated plots received on average $25 \%$ more water per month based on monthly rainfall averages between 1967 and 2011 rainfall data gathered from the Subiaco treatment plant, Station \#9151. For differences in soil moisture between soil depths please see Fig. S5 
Root lifespan and predicted survival

Survivorship of woody roots was greater than that of all other root types (Fig. 3). Furthermore, all other root types had greater survivorship than rootlets from cluster roots (Fig. 3). Indeed, cluster rootlets had an overall mean lifespan of only 23 days (Fig. 3) and mean depth of occurrence was $12 \mathrm{~cm}$. The main axes of cluster roots sometimes survived after the emergence of the rootlets, and we estimated an overall mean lifespan of 30 days when this feature was taken into account. We did not find a significant relationship between cluster-rootlet lifespan and depth; however, we found a higher frequency of occurrence of cluster-root emergence below $10 \mathrm{~cm}$ (10 counts compared with 2 for the 3 to $10 \mathrm{~cm}$ depth; $\chi^{2}=5.33, P$-value $\left.=0.021\right)$. However, survivorship of cluster roots appeared slightly greater above $10 \mathrm{~cm}$ (Fig. S6).

Root survival of all root types, taken together, was considerably longer and sustained lower in the soil profile compared with that of roots forming near the

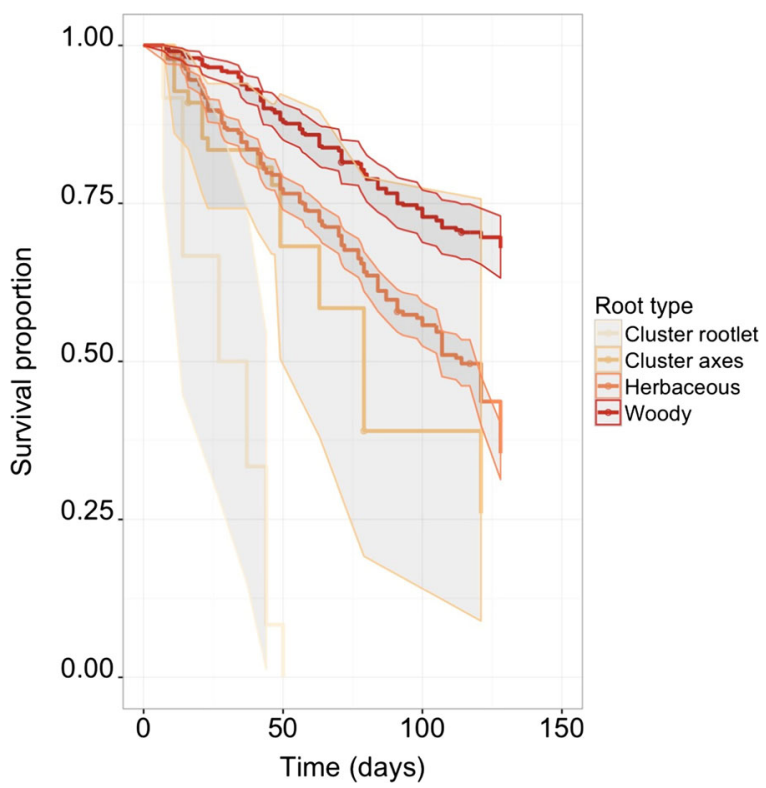

Fig. 3 Survivorship of the general root types (cluster axes, herbaceous, cluster rootlets, and woody) produced from April to October, 2012 across all plots (with or without irrigation) in a eucalypt-banksia woodland. Grey shaded areas represent $95 \%$ confidence limits. Survivorship of cluster roots (i.e. Root Type $=$ Cluster axes) includes the main root axis and rootlets; on many occasions the rootlets died, yet the main axis of the cluster root appeared alive; therefore, we also show the survivorship of rootlets on their own (i.e. Root Type $=$ Cluster rootlet). Survival curves with non-overlapping $95 \%$ confidence limits were considered significantly different but also see Table $\mathrm{S} 1$ for specific tests surface (Fig. 4). This effect was particularly strong for woody roots as $\sim 80 \%$ of the surviving woody roots were found in the lower 21 to $40 \mathrm{~cm}$ (Fig. 4). Non-woody roots showed more variation and the survival appeared mostly invariant with depth (Fig. 4). Overall, irrigation affected the survival of non-woody roots, but only after 100 days (Fig. 5). Frequency analysis showed that irrigation promoted a greater occurrence of cluster roots compared with that in non-irrigated plots (Irrigation $=64$ cluster roots; non-irrigated $=2$ cluster roots; $\chi^{2}=58.2$, $P$-value $<0.001)$; however, the low number of cluster roots in the non-irrigated plots did not allow an analysis of the survival rate and lifespan in that treatment.

a) All root types

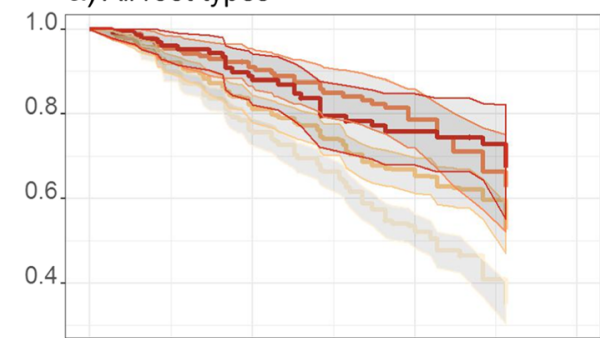

b) Woody roots

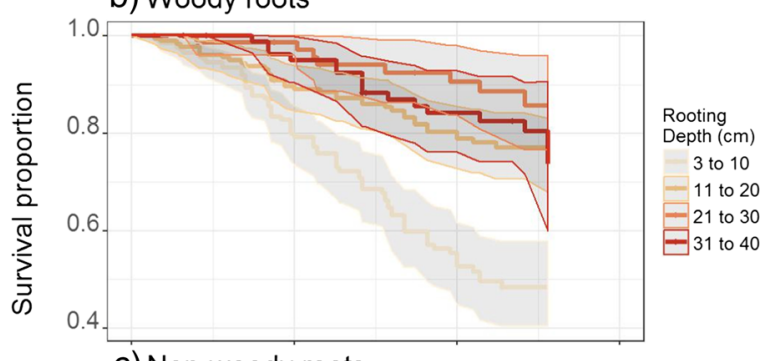

c) Non-woody roots

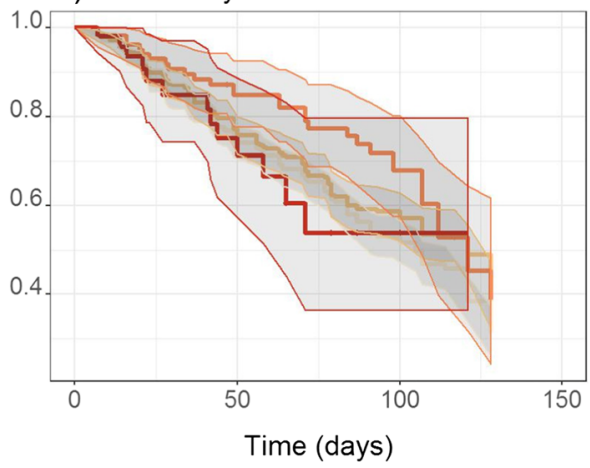

Fig. 4 Survivorship of a) all root types, the b) woody, and c) nonwoody roots with soil depth produced from April to October, 2012 across all plots (with or without irrigation) in a eucalypt-banksia woodland. Grey shaded areas represent $95 \%$ confidence limits. Survival curves with non-overlapping $95 \%$ confidence limits were considered significantly different but also see Table $\mathrm{S} 1$ for specific tests 


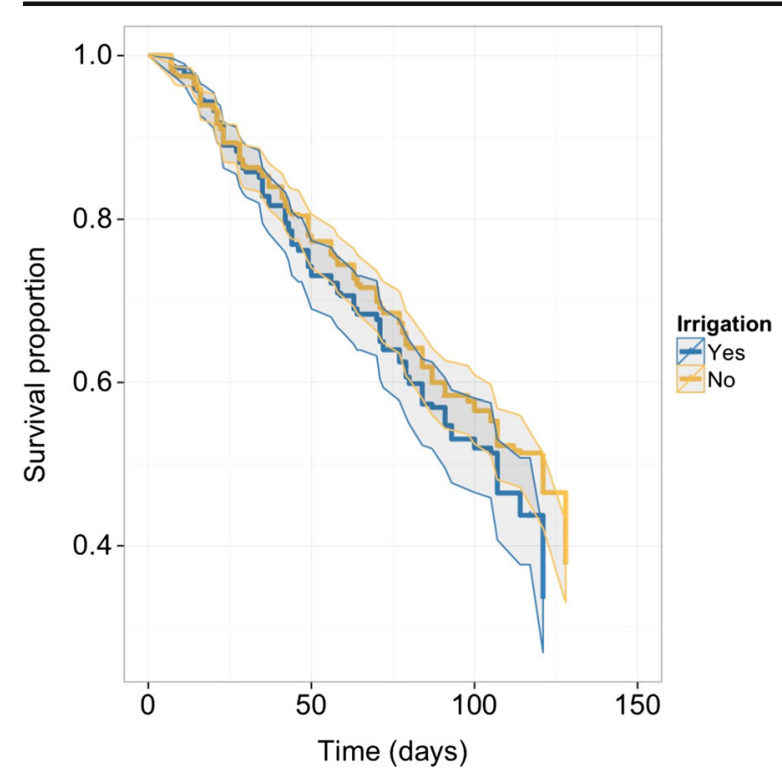

Fig. 5 Survivorship of the non-woody roots produced from April to October, 2012 with or without irrigation in a eucalypt-banksia woodland. Grey shaded areas represent $95 \%$ confidence limits. Survival curves with non-overlapping $95 \%$ confidence limits were considered significantly different but also see Table S1 for specific tests

Root responses to soil moisture, irrigation, and soil depth

There was no significant relationship between soil moisture and root production, or proportion of surviving roots (Fig. S7). However, root lifespan was affected by irrigation and soil depth additively (Fig. 6), where irrigated plots had lower lifespans than non-irrigated plots (Fig. 6a) and the upper $10 \mathrm{~cm}$ had lower lifespans than the $11-50 \mathrm{~cm}$ depth range for the woody roots (Fig. $6 \mathrm{~b}$ ). Furthermore, the proportion of surviving roots was lower in the upper $10 \mathrm{~cm}$ than in the $11-50 \mathrm{~cm}$ depth range for all roots (Fig. 6c) and woody roots Fig. 6d).

\section{Root dynamics}

The root production rate throughout the experimental period had marked peaks and lows early in the rainy winter months (Fig. S8). Root mortality rate increased gradually throughout the sampling period, whereas root production was more variable (Fig. S8). Standing crop was initially very low in the 'no irrigation' treatment, but from June onwards was considerably greater than that in the irrigated treatment (Fig. S8; Table 1). From June to October,
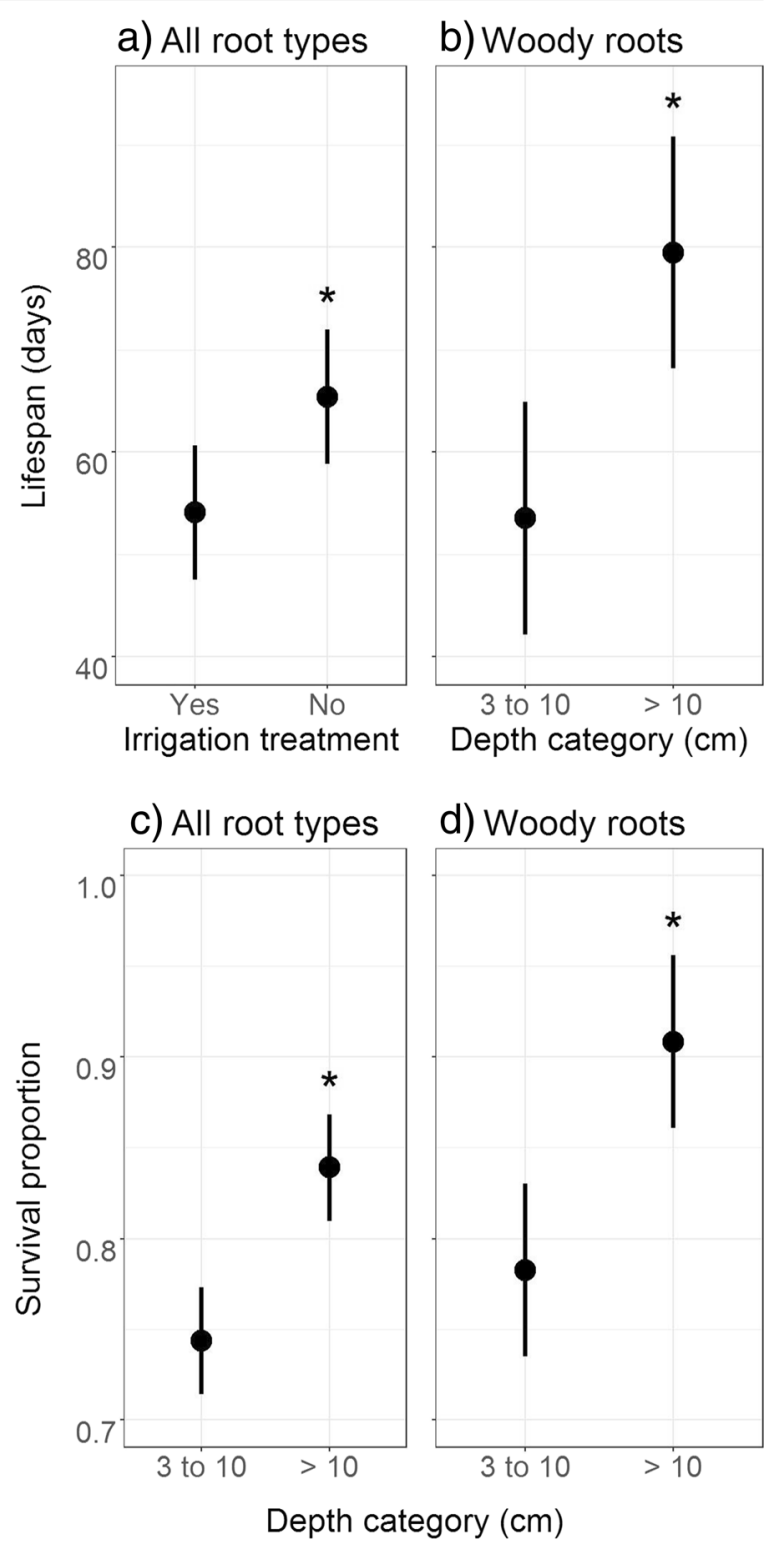

Fig. 6 Root lifespan of a) all root types for the two irrigation treatments, lifespan of $\mathbf{b}$ ) woody roots for the two soil depth ranges; root survival of c) all root types, and of $\mathbf{d}$ ) woody roots for the two soil depth ranges during the 2012 measurement period in a eucalypt-banksia woodland at the Shenton Park Field Station. Values are means with $95 \%$ confidence intervals and asterisks (*) identify statistically significantly different means following a Student's $t$-Test. Irrigated plots received on average $25 \%$ more water per month based on monthly rainfall averages between 1967 and 2011 rainfall data gathered from the Subiaco treatment plant, Station \#9151

standing crop gradually increased; in early October, mortality significantly increased suddenly (Table 1; Fig. S8). Differences in root production and 
standing crop between irrigation treatments within specific months were found, although these were a result of significant interactions between 'time' effects and the irrigation treatment (Table 1). In particular, greater root production with irrigation occurred in April (Table 2).

\section{Discussion}

Root dynamics showed some resilience to changes in arrival and total rainfall during the winter months in this Mediterranean woodland. Lower soil moisture did have some notable yet specific effects; decreased root production in April, increased lifespan of non-woody roots, and lower frequency of occurrence of cluster roots was found.

Cluster-root emergence and soil moisture

Cluster roots and their fine rootlets occurred almost exclusively under the irrigation treatment (i.e. greater soil moisture availability). The overall increase in soil moisture levels from 13.4 to $16.2 \%$ resulting from the increased amount of water received by the irrigated plots $(23.1 \%$ more compared with the non-irrigated plots), or the greater frequency of soil wetting, appeared to have promoted the production of a considerably greater number of cluster roots. These findings partly support previous field observations on cluster-root emergence and rainfall events (Lamont 2003), suggesting a minimum soil moisture threshold is required for deployment of cluster roots. However, our results may also indicate that an increase in soil moisture, regardless of a minimum threshold, can trigger cluster-root formation. More

Table 1 Summary of repeated measures analysis of variance for the standing crop (total length of all live roots), root production (length of newly appeared roots plus root extensions of existing roots), and root mortality (the length of non-recurring roots plus importantly, the lower frequency of cluster roots in relatively drier soils suggest that potentially less $\mathrm{P}$ may be mobilised and cycled in this system if rainfall continues to decline due to climate change. This ecosystem is not limited by light, and thus when adequate water levels (i.e. above a minimum soil moisture threshold) are present in soil, resource allocation to cluster roots occurs as a 'pulse' maximising $\mathrm{P}$ acquisition. This information is known (Lamont 1982; Lamont 2003); however, we show this, for the first time, with more precise in situ observations of individual cluster roots in mixed species-rich plant communities.

Root lifespan and soil moisture

Root lifespan (all types) was slightly lowered by irrigation (i.e. greater soil moisture) and this effect was more evident with non-woody roots, particularly towards the end of the winter months. There are insufficient data to discuss mechanisms behind these trends; however, there are likely key factors such as temperature, rainfall, soil nutrient availability, seasonality, and phenological features that control root lifespan in this system. .

Root lifespan within major plant groups and in response to soil depth

Cluster roots had shorter lifespans than the other root types, at slightly lower levels to what has been observed for other non-mycorrhizal woody roots (Vogt and Bloomfield 1996; Eissenstat et al. 2000; Chen and Brassard 2013). It is expected that cluster roots would die after soil resources have been depleted thus maximising nutrient-uptake efficiency by only supporting roots that have functional importance

the length of roots that appeared dead). Linear mixed effect models with adjustments to the residual correlation structure were used (Zuur et al. 2009). Statistically significant $P$-values are given in bold

\begin{tabular}{|c|c|c|c|c|c|c|c|c|c|c|}
\hline & \multirow[b]{2}{*}{$\mathrm{df}_{\mathrm{N}}$} & \multirow[b]{2}{*}{$\mathrm{df}_{\mathrm{D}}$} & \multicolumn{2}{|c|}{ Standing crop } & \multirow[b]{2}{*}{$\mathrm{df}_{\mathrm{N}}$} & \multirow[b]{2}{*}{$\mathrm{df}_{\mathrm{D}}$} & \multicolumn{2}{|c|}{ Mortality } & \multicolumn{2}{|c|}{ Production } \\
\hline & & & $F$ & $P$ & & & $F$ & $P$ & $F$ & $P$ \\
\hline Irrigation & 1 & 8 & 0.11 & 0.741 & 1 & 8 & 0.01 & 0.914 & 2.87 & 0.128 \\
\hline Time* & 6 & 163 & 3.51 & 0.003 & 5 & 122 & 5.02 & $<0.001$ & 12.68 & $<0.001$ \\
\hline Irrigation $\mathrm{x}$ Time & 6 & 163 & 3.63 & 0.002 & 5 & 122 & 1.15 & 0.316 & 3.38 & 0.006 \\
\hline
\end{tabular}

*Time was included as an average of each sampling month 
(Shane and Lambers 2005). This, in part, explains why the rootlets from cluster roots had very short lifespan (23 days on average). We found that the lifespan of roots in general was longer lower in the soil profile, indicating that cluster roots live longer at greater depth. However, in deeper soil layers there are less soil-based resources (Jobbágy and Jackson 2001; Laliberté et al. 2012); therefore, resource investment in this strategy at lower depths is less efficient under adequate rainfall. We could not draw any general conclusion, since we did not observe enough cluster roots emerging in the nonirrigated plots to run more than simple frequency analysis. Thus, we suggest future research to include more replication and/or perhaps include more than one year of imaging.

We found predictable differences in root lifespan over the winter months for the four identifiable root types. Cluster rootlets had short lifespans, 23 days on average, confirming previous observations from hydroponic studies (Shane et al. 2004; Shane and Lambers 2005). Woody roots, on the other hand, had the greatest longevities compared with all other root types. We could not determine median lifespan (number of days to reach $50 \%$ mortality) for woody roots, since we did not image long enough, but lifespan was similar to what has been recorded for tree roots in temperate forests (Fahey and Hughes 1994; Burton et al. 2000). This result suggests that woody-rooted plants in this Mediterranean-climate system maintain their roots as long as possible given the relatively low carbon costs to maintain activity (Janssens et al. 2002). Overall, in all root types, lifespan increased with soil depth, a particularly common feature in Mediterranean and other semi-arid ecosystems with long periods without rainfall (Wu et al. 2013), but also observed in other ecosystems (Chen and Brassard 2013). Woody roots also showed the strongest pattern of greater lifespan in deeper soil compared with that in surface soil. This could also result from the fact that woody roots tended to have larger diameters, a root trait that correlates positively with root lifespan (Hendrick and Pregitzer 1996; Steinaker and Wilson 2005; Wu et al. 2013).

Root dynamics and a declining rainfall regime

Root dynamics (standing crop, mortality, and production) were mostly unresponsive to an increase in soil moisture levels (irrigated plots) over the winter months. Overall, mean root production and the proportion of surviving roots were also invariant to soil moisture levels. These 
findings suggest that the system has some belowground resilience to reduced rainfall. In April, however, we found a considerable decrease in root production in the nonirrigated plots (ambient rainfall), which may support the concept that later arrival of rainfall, as predicted by climate models, may ultimately lower root production in this ecosystem due to a reduction in the length of the growing season. However, this concept was not fully supported in our system since there was one large rain event in late April. Nevertheless, root production adjusted in the non-irrigated plots to levels comparable to irrigated plots later in the season. Although recent drought events have reduced health and growth of trees in Mediterranean ecosystems (Sarris et al. 2007; Carnicer et al. 2011; Poot and Veneklaas 2012), the forest structure remained largely intact, suggesting there is 'climate pre-adaptation' or resilience in these ecosystems (Lloret et al. 2012), or a critical soil moisture threshold was not reached.

Root dynamics in arid or semi-arid environments typically shows more variable effects of soil moisture compared with that in more mesic environments (Hendrick and Pregitzer 1997; Gill and Jackson 2000; Tierney et al. 2003). The plants' preferential reliance on surface- vs. deep-water sources may be an important factor affecting root dynamics under shifts in rainfall regime. More arid ecosystems tend to be highly sensitive to increased rainfall; for example, in arid grasslands, highly-sensitive responses to increases in rainfall have been observed, where aboveground net primary productivity increased considerably after a rainfall treatment of $30 \%$ above historical averages (Thomey et al. 2011). Altered aboveground responses to shifts in rainfall are more consistently observed (Hamerlynck et al. 2000; Schwinning et al. 2005) than what has been recorded with roots (Bai et al. 2010; Verburg et al. 2013; Padilla et al. 2015). Furthermore, there are many examples that show that even if aboveground responses to altered environmental conditions are seen, roots may not be affected (Nowak et al. 2004; Phillips et al. 2006). As such, our study suggests that root responses are possibly decoupled from the plant's aboveground responses to changing environmental conditions (Weemstra et al. 2016). This may, in part, be due to the multiple interacting factors and complexity driving root production under scenarios of climate change such as temperature and precipitation that have interactive effects (Bai et al. 2010) and/or since there are many aboveground plant responses (e.g., photosynthesis, carbon allocation to roots) also affecting root growth.
Root abundance (i.e. root standing crop) remained greater without irrigation (i.e. ambient rainfall levels) compared with that in the irrigated plots, as observed in other ecosystems (Joslin and Wolfe 1998; Verburg et al. 2013). Also in line with our results is the enhanced root density found in conjunction with a $30 \%$ reduction of rainfall in an arid shrubland (Padilla et al. 2015). Such counterintuitive responses to lower rainfall appear to be the result of an adaptive strategy to overcome the negative effects of lower water availabilities (Metcalfe et al. 2008). To achieve this, plants may increase their allocation of resources to roots in response to lower water availabilities. Nevertheless, there are good examples of plants responding to reduced rainfall in other ecosystems by decreasing root production (Majdi and Andersson 2005; Fiala et al. 2009; Bai et al. 2010; Meier and Leuschner 2010). Our results and those of others clearly show that root responses are complex and not easily predicted.

\section{Concluding remarks}

Root dynamics in this Mediterranean ecosystem showed some level of resilience to changes in arrival of and total water inputs (irrigation and rainfall) during the winter months. The effects of irrigation, root type, and soil depth on root dynamics were largely as expected. Cluster roots were affected by soil moisture levels, and they showed much greater frequency of occurrence in the irrigated plots. Since plants that produce cluster roots are prominent in this diverse Mediterranean ecosystem, we propose that plant species compositional shifts may continue to occur (Crosti et al. 2007; Fisher et al. 2009) due to a drying climate, if: i) cluster-rooted plants become less efficient in mining soil $\mathrm{P}$ due to narrower 'windows' of favorable soil moisture conditions, and ii) if $\mathrm{P}$ and micronutrient uptake of coexisting plants is indeed facilitated by the root activity of cluster-rooted plants. Future research should address both possibilities; we are currently addressing the second possibility by better understanding the interactions between clusterroot emergence and other intermingling roots.

Acknowledgements Michael Blair and Raymond Scott provided help at the start of the experimental setup and tube installations and for facilitating access to the field station. We are indebted to Bryden Quirk and David D. Sampson (Optical + Biomedical Engineering Laboratory) at the School of Electrical, Electronic \& Computer Engineering at UWA for building a high-resolution minirhizotron camera and helping gather the first set of images. 
We are grateful to Jairo Palta, then at CSIRO in Floreat, for loaning the Bartz minirhizotron camera. Thomas Mazet played a key role with imaging during rainy days. We are especially grateful to Judith Holmes, Cynthia Playford, and Ruby Johnson of the 'Friends of Kings Park' for their valuable help during the plant identification and root annotation with RootFly. Funding was provided by The University of Western Australia with a Research and Development Award granted to FT and the Australian Research Council with a Discovery Project (ARC DP0985685) to HL, EV and KD.

Author contributions FPT, HL, KWD, and EJV originally formulated the idea, FPT, KWD, and EJV developed methodology, FPT conducted fieldwork, FPT generated the images, VAM and FPT analysed the images, FPT performed statistical analyses, and FPT, VAM, HL, KWD, and EJV wrote the manuscript.

\section{References}

Bai W, Wan S, Niu S, Liu W, Chen Q, Wang Q, Zhang W, Han X, Li L (2010) Increased temperature and precipitation interact to affect root production, mortality, and turnover in a temperate steppe: implications for ecosystem $\mathrm{C}$ cycling. Glob Chang Biol 16:1306-1316

Burton A, Pregitzer K, Hendrick R (2000) Relationships between fine root dynamics and nitrogen availability in Michigan northern hardwood forests. Oecologia 125:389-399

Carnicer J, Coll M, Ninyerola M, Pons X, Sanchez G, Peñuelas J (2011) Widespread crown condition decline, food web disruption, and amplified tree mortality with increased climate change-type drought. Proc Natl Acad Sci U S A 108:14741478

Chen HYH, Brassard BW (2013) Intrinsic and extrinsic controls of fine root life span. Crit Rev Plant Sci 32:151-161. doi:10.1080/07352689.2012.734742

Crosti R, Dixon K, Ladd P, Yates C (2007) Changes in the structure and species dominance in vegetation over 60 years in an urban bushland remnant. Pac Conserv Biol 13:158-170

Denton MD, Veneklaas EJ, Lambers H (2007) Does phenotypic plasticity in carboxylate exudation differ among rare and widespread Banksia species (Proteaceae)? New Phytol 173:592-599

Diffenbaugh NS, Field CB (2013) Changes in ecologically critical terrestrial climate conditions. Science 341:486-492

Dodd J, Heddle EM, Pate JS, Dixon KW (1984) Rooting patterns of sandplain plants and their functional significance. In: Pate JS, Beard JS (eds) Kwongan, plant life of the sandplain: biology of a south-west Australian shrubland ecosystem. UWA Press, Nedlands

Eissenstat DM, Wells CE, Yanai RD, Whitbeck JL (2000) Building roots in a changing environment: implications for root longevity. New Phytol 147:33-42. doi:10.1046/j.14698137.2000.00686.x

Fahey TJ, Hughes JW (1994) Fine root dynamics in a northern hardwood forest ecosystem, Hubbard brook experimental Forest, NH J Ecol 533-548
Fiala K, Tůma I, Holub P (2009) Effect of manipulated rainfall on root production and plant belowground dry mass of different grassland ecosystems. Ecosystems 12:906-914

Finér L, Ohashi M, Noguchi K, Hirano Y (2011) Fine root production and turnover in forest ecosystems in relation to stand and environmental characteristics. For Ecol Manag 262: 2008-2023

Fisher JL, Loneragan WA, Dixon K, Delaney J, Veneklaas EJ (2009) Altered vegetation structure and composition linked to fire frequency and plant invasion in a biodiverse woodland. Biol Conserv 142:2270-2281

Gill RA, Jackson RB (2000) Global patterns of root turnover for terrestrial ecosystems. New Phytol 147:13-31

Hamerlynck EP, McAuliffe JR, Smith SD (2000) Effects of surface and sub-surface soil horizons on the seasonal performance of Larrea tridentata (creosotebush). Funct Ecol 14:596-606

Harrington DP, Fleming TR (1982) A class of rank test procedures for censored survival data. Biometrika 69:553-566

Hendrick RL, Pregitzer KS (1996) Applications of minirhizotrons to understand root function in forests and other natural ecosystems. Plant Soil 185:293-304

Hendrick RL, Pregitzer KS (1997) The relationship between fine root demography and the soil environment in northern hardwood forests. Ecoscience 4:99-105

Hopper SD, Gioia P (2004) The southwest Australian floristic region: evolution and conservation of a global hot spot of biodiversity. Annu Rev Ecol Evol Syst 35:623-650

Huang B, Nobel PS (1992) Hydraulic conductivity and anatomy for lateral roots of Agave deserti during root growth and drought-induced abscission. J Exp Bot 43:1441-1449

Initiative IOC (2012) Western Australia's weather and climate: a synthesis of Indian Ocean climate Initiative stage 3 research. Commonwealth of Australia, Melbourne

Janssens I, Sampson D, Curiel-Yuste J, Carrara A, Ceulemans R (2002) The carbon cost of fine root turnover in a scots pine forest. For Ecol Manag 168:231-240

Jobbágy EG, Jackson RB (2001) The distribution of soil nutrients with depth: global patterns and the imprint of plants. Biogeochemistry 53:51-77. doi:10.1023/a:1010760720215

Johnson M, Rygiewicz P, Tingey D, Phillips D (2006) Elevated $\mathrm{CO}_{2}$ and elevated temperature have no effect on Douglas-fir fine-root dynamics in nitrogen-poor soil. New Phytol 170: 345-356

Joslin JD, Wolfe MH (1998) Impacts of water input manipulations on fine root production and mortality in a mature hardwood forest. Plant Soil 204:165-174

Laliberté E, Turner BL, Costes T, Pearse SJ, Wyrwoll KH, Zemunik G, Lambers H (2012) Experimental assessment of nutrient limitation along a 2-million-year dune chronosequence in the south-western Australia biodiversity hotspot. J Ecol 100:631-642

Lambers H, Shane MW, Cramer MD, Pearse SJ, Veneklaas EJ (2006) Root structure and functioning for efficient acquisition of phosphorus: matching morphological and physiological traits. Ann Bot 98:693-713

Lambers H, Shane M, Laliberté E, Swarts N, Teste F, Zemunik G (2014) Plant mineral nutrition. In: Lambers H (ed) Plant life on the sandplains in Southwest Australia, a global biodiversity hotspot. UWA Publishing, Crawley

Lambers H, Clode PL, Hawkins H-J, Laliberte E, Oliveira RS, Reddell P, Shane MW, Stitt M, Weston P (2015) Metabolic 
adaptations of the non-mycotrophic proteaceae to soils with low phosphorus. In: Plaxton W, Lambers H (eds) Annual plant reviews, phosphorus metabolism in plants. JohnWiley \& Sons, Ltd., Hoboken

Lamont BB (1976) The effects of seasonality and waterlogging on the root systems of a number of Hakea species. Aust J Bot 24: 691-702

Lamont B (1982) Mechanisms for enhancing nutrient uptake in plants, with particular reference to mediterranean South Africa and Western Australia. Bot Rev 48:597-689

Lamont BB (2003) Structure, ecology and physiology of root clusters - a review. Plant Soil 248:1-19

Lloret F, Escudero A, Iriondo JM, Matinex-Vilalta J, Valladares F (2012) Extreme climate events and vegetation: the role of stabilizing processes. Glob Chang Biol 18:797-805

Majdi H, Andersson P (2005) Fine root production and turnover in a Norway spruce stand in northern Sweden: effects of nitrogen and water manipulation. Ecosystems 8:191-199

McArthur WM, Bettenay E (1974) The development and distribution of the soils of the Swan coastal Plain. CSIRO, Australia

Meier IC, Leuschner C (2010) Variation of soil and biomass carbon pools in beech forests across a precipitation gradient. Glob Chang Biol 16:1035-1045. doi:10.1111/j.13652486.2009.02074.x

Metcalfe DB, Meir P, Aragão LEO, da Costa AC, Braga AP, Gonçalves PH, Junior JAS, de Almeida SS, Dawson LA, Malhi Y (2008) The effects of water availability on root growth and morphology in an Amazon rainforest. Plant Soil 311:189-199

Muler AL, Oliveira RS, Lambers H, Veneklaas EJ (2014) Does cluster-root activity benefit nutrient uptake and growth of coexisting species? Oecologia 174:23-31

Myers N, Mittermeier RA, Mittermeier CG, Da Fonseca GA, Kent J (2000) Biodiversity hotspots for conservation priorities. Nature 403:853-858

Nowak RS, Ellsworth DS, Smith SD (2004) Functional responses of plants to elevated atmospheric $\mathrm{CO}_{2}-$ do photosynthetic and productivity data from FACE experiments support early predictions? New Phytol 162:253-280

Padilla FM, de Dios MJ, Armas C, Pugnaire FI (2015) Effects of changes in rainfall amount and pattern on root dynamics in an arid shrubland. J Arid Environ 114:49-53

Phillips DL, Johnson MG, Tingey DT, Catricala CE, Hoyman TL, Nowak RS (2006) Effects of elevated $\mathrm{CO}_{2}$ on fine root dynamics in a Mojave Desert community: a FACE study. Glob Chang Biol 12:61-73. doi:10.1111/j.13652486.2005.01085.x

Poot P, Veneklaas EJ (2012) Species distribution and crown decline are associated with contrasting water relations in four common sympatric eucalypt species in southwestern Australia. Plant Soil 364:409-423. doi:10.1007/s11104012-1452-8

R Core Team (2016) R: a language and environment for statistical computing. R Foundation for Statistical Computing, Vienna

Sarris D, Christodoulakis D, Körner C (2007) Recent decline in precipitation and tree growth in the eastern Mediterranean. Glob Chang Biol 13:1187-1200

Schwinning S, Starr BI, Ehleringer JR (2005) Summer and winter drought in a cold desert ecosystem (Colorado plateau) part I: effects on soil water and plant water uptake. J Arid Environ 60:547-566
Shane MW, Lambers H (2005) Cluster roots: a curiosity in context. Plant Soil 274:101-125

Shane MW, Cramer MD, Funayama-Noguchi S, Cawthray GR, Millar AH, Day DA, Lambers H (2004) Developmental physiology of cluster-root carboxylate synthesis and exudation in harsh hakea. Expression of phosphoenolpyruvate carboxylase and the alternative oxidase. Plant Physiol 135:549-560

Smit AL, Bengough A, Engels C, van Noordwijk M, Pellerin S, van de Geijn S (2000) Root methods: a handbook. Springer, New York

Steinaker DF, Wilson SD (2005) Belowground litter contributions to nitrogen cycling at a northern grassland-forest boundary. Ecology 86:2825-2833

Teste FP, Veneklaas EJ, Dixon KW, Lambers H (2014) Complementary plant nutrient-acquisition strategies promote growth of neighbour species. Funct Ecol 28:819-828

Therneau T (2014) A package for survival analysis in S. R package version 2.37-7 edn

Therneau T, Grambsch P (2000) Modeling survival data: extending the cox model. Springer-Verlag, New York

Thomey M, Collins S, Vargas R, Johnson J, Brown R, Natvig D, Friggens M (2011) Effect of precipitation variability on net primary production and soil respiration in a Chihuahuan Desert grassland. Glob Chang Biol 17:1505-1515

Tierney GL, Fahey TJ, Groffman PM, Hardy JP, Fitzhugh RD, Driscoll CT, Yavitt JB (2003) Environmental control of fine root dynamics in a northern hardwood forest. Glob Chang Biol 9:670-679

Verburg PSJ, Young AC, Stevenson BA, Glanzmann I, Arnone JA, Marion GM, Holmes C, Nowak RS (2013) Do increased summer precipitation and $\mathrm{N}$ deposition alter fine root dynamics in a Mojave Desert ecosystem? Glob Chang Biol 19:948956. doi:10.1111/gcb.12082

Vogt KA, Bloomfield J (1996) Tree root turnover and senescence. In: Y Waisel, a Eshel, U Kafkafi (eds) plant roots: the hidden half. 2nd edition edn. Marcel Dekker Inc., New York

Weemstra M, Mommer L, Visser EJW, van Ruijven J, Kuyper TW, Mohren GMJ, Sterck FJ (2016) Towards a multidimensional root trait framework: a tree root review. New Phytol 211: 1159-1169. doi:10.1111/nph.14003

Wickham H (2009) ggplot2: elegant graphics for data analysis. Springer, New York

Wright AJ, Wardle DA, Callaway R, Gaxiola A (2017) The overlooked role of facilitation in biodiversity experiments. Trends Ecol Evol. doi:10.1016/j.tree.2017.02.011

Wu Y, Deng Y, Zhang J, Wu J, Tang Y, Cao G, Zhang F, Cui X (2013) Root size and soil environments determine root lifespan: evidence from an alpine meadow on the Tibetan plateau. Ecol Res 28:493-501. doi:10.1007/s11284-0131038-9

Wyrwoll K-H, Turner BL, Findlater P (2014) 1a. On the origins, geomorphology and soils of the sandplains of south-western Australia. In: Lambers H (ed) Plant life on the sandplains in Southwest Australia, a global biodiversity hotspot. UWA Publishing, Crawley

Zeng G, Birchfield ST, Wells CE (2010) Rapid automated detection of roots in minirhizotron images. Mach Vis Appl 21: 309-317

Zuur AF, Leno EN, Walker NJ, Saveliev AA, Smith GM (2009) Mixed effects models and extensions in ecology with R. Springer, New York, NY, USA 